\title{
A Review of Drug Therapy in Vestibular Schwannoma
}

This article was published in the following Dove Press journal:

Drug Design, Development and Therapy

\author{
Jianfei Long $\mathbb{B D}^{1, *}$ \\ Yu Zhang ${ }^{1, *}$ \\ Xiang Huang ${ }^{2}$ \\ Junwei $\operatorname{Ren}^{2}$ \\ Ping Zhong ${ }^{2}$ \\ Bin Wang'
}

'Department of Pharmacy, Huashan Hospital, Fudan University, Shanghai, People's Republic of China; ${ }^{2}$ Department of Neurosurgery, Huashan Hospital, Fudan University, Shanghai, People's Republic of China

*These authors contributed equally to this work
Correspondence: Ping Zhong Department of Neurosurgery, Huashan Hospital, Fudan University, No. 12 Middle Wu Lu Mu Qi Road, Shanghai 200040,

People's Republic of China Email zhp228899@163.com

Bin Wang

Department of Pharmacy, Huashan

Hospital, Fudan University, No. 12 Middle

Wu Lu Mu Qi Road, Shanghai 200040,

People's Republic of China

Tel +86 I391660672I

Email wangbin@huashan.org.cn

\begin{abstract}
Vestibular schwannomas (VSs, also known as acoustic neuromas) are benign intracranial tumors commonly managed with observation, surgery, and radiotherapy. There is currently no approved pharmacotherapy for VS patients, which is why we conducted a detailed search of relevant literature from PubMed and Web of Science to explore recent advances and experiences in drug therapy. VSs feature a long course of disease that requires treatment to have minimal long-term side effects. Conventional chemotherapeutic agents are characterized by neurotoxicity or ototoxicity, poor effect on slow-growing tumors, and may induce new mutations in patients who have lost tumor suppressor function, and therefore are unsuitable for treating VSs. Along with the well-investigated molecular pathophysiology of VS and the increasingly accessible technology such as drug repositioning platform, many molecular targeted inhibitors have been identified and shown certain therapeutic effects in preclinical experiments or clinical trials.
\end{abstract}

Keywords: vestibular schwannomas, drug therapy, therapeutic targets, VEGFR inhibitor

\section{Introduction}

As the most common tumors of the cerebellopontine angle and the fourth most common intracranial neoplasms, vestibular schwannomas (VSs) are histopathologically benign neoplasms that typically originate from Schwann cells lining cranial nerve VIII (vestibular nerve). Neurosurgeons have determined that hearing loss, deafness, and tinnitus are common clinical manifestations in the early stages of VSs, and that progressive VSs are likely to impact lower cranial nerves and the brainstem, leading to facial paresthesia, ataxia and vertigo. ${ }^{1}$ With the progress of diagnosis and treatment technology, the main purpose of VS management has changed from saving patients' lives to preserving complete neurological function and improving their quality of life.

VSs can occur unilaterally, as sporadic lesions, or bilaterally, as a part of autosomal dominantly inherited disorder neurofibromatosis type 2 (NF2). About $60 \%$ of unilateral VSs and $90 \%$ of bilateral cases demonstrate the mutation of the NF2 gene and the dysfunction of its transcription product, merlin (Moesin-ezrinradixin-like protein). ${ }^{2,3}$ Strategies for managing patients with sporadic VS are observation, surgery, and radiotherapy. Over the 3.6-year follow-up, the average growth rate for sporadic tumors was $1.1 \mathrm{~mm} /$ year, suggesting that "wait and rescan" with serial MRIs is a safe choice for small and stable tumors $(<2 \mathrm{~cm})$, as well as for elderly patients, whose treatment is associated with a higher mortality rate. ${ }^{4}$ However, this tactic is associated with risk of tumor growth and poor hearing 
outcomes. Surgical treatment can cause significant trauma to patients, thus it is only preferable in patients with symptoms of brainstem compression or with small but fast-growth tumors. Radiotherapy is suitable for small growing tumors and small tumors with an irregular outline. Additionally, pseudo progression, damage to cochlear hair cells, delayed hearing loss, and surgically challenging post-stereotactic radiosurgery should be taken into consideration. $^{5-7}$ NF2-VSs are more lobulated, grow more quickly, present at a younger age, tend to be larger, envelop adjacent cochlear and facial nerves, and may coexist with schwannomas of the facial and cochlear nerves, making the cleavage plane between the facial nerve and the tumor difficult to determine, thus higher risk of nerve damage secondary to surgery. ${ }^{8,9}$ It is widely accepted that radiotherapy is less effective in treating NF2VSs than treating sporadic VSs. ${ }^{10}$

The growing understanding of the mechanisms by which merlin dysregulation induces disease, as well as of signal pathways related to VS growth, has raised hopes for the application of targeted therapies. Merlin plays a significant role in regulating the process mediated by the actin cytoskeleton, adhesion junction formation, and cell proliferation. ${ }^{11}$ Recent studies have suggested that merlin can regulate multiple pathways implicated in tumorigenesis including retrovirusassociated DNA sequences (Ras)/rapidly accelerated fibrosarcoma (Raf)/mitogen extracellular signalregulated kinase (MEK)/extracellular-signal-regulated kinases (ERK), mammalian target of rapamycin complex 1 (mTORC1), Rac/p21-activated kinase (PAK)/C-Jun kinase, phosphoinositide 3-kinase (PI3K)/Akt and the intranuclear E3 ubiquitin ligase CRL4 (DCAF1) (Figure 1). ${ }^{12-17}$ All of these proposed sites are potential therapeutic targets of VS.

\section{Methods}

To conduct this literature review, we searched the databases of PubMed and Web of Science to identify studies published between 2010 and 2020, which included the terms "vestibular schwannoma" or "acoustic neuroma," in addition to "drug," "medicine," "therapy," or "treatment." Additionally, we manually searched the reference list of the retrieved articles and summarized therapeutic targets currently under consideration and pharmacotherapy in cell studies, animal experiments, and clinical trials in vestibular schwannoma.

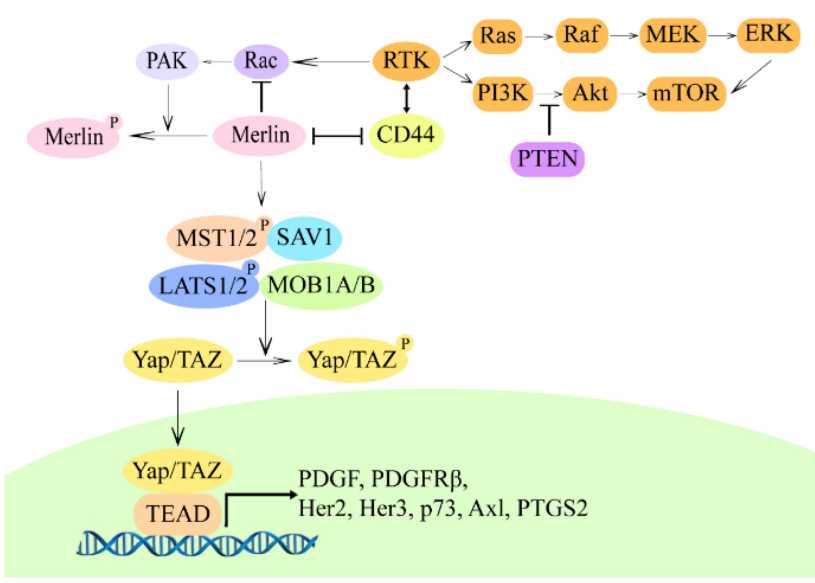

Figure I Signal pathways related to merlin dysregulation.

Notes: After merlin inactivation, RTK and its downstream Ras/Raf/MEK/ERK and $\mathrm{PI} 3 \mathrm{~K} / \mathrm{Akt} / \mathrm{mTOR}$ signaling pathways are abnormally activated. In addition, merlin inhibits the phosphorylation of Yap/TAZ downstream of the Hippo pathway, allowing more Yap/TAZ into the nucleus and binds to TEAD, promoting the transcription of PDGF, PDGFR $\beta$ and PTGS2.

Abbreviations: PAK, P2I-activated kinase; RTK, receptor protein tyrosine kinase; Ras, retrovirus-associated DNA sequences; Raf, rapidly accelerated fibrosarcoma; MEK, mitogen extracellular signal-regulated kinase; ERK, extracellular-signalregulated kinases; PI3K, phosphoinositide 3-kinase; mTOR, mammalian target of rapamycin; Yap, Yes-associated protein; TAZ, TEAD; PDGF, platelet-derived growth factor; PDGFR, platelet-derived growth factor receptor; PTGS2, prostaglandin G/H synthase 2 .

\section{Results}

\section{Protein Tyrosine Kinase Inhibitor}

The transfer of the phosphate groups on adenosine triphosphate (ATP) to determined target proteins is catalyzed by kinases, which are the primary mediators in cell signal transduction that regulate cell differentiation, growth, migration, and apoptosis. As a type of kinase that catalyzes the transfer of phosphate from ATP to protein tyrosine residues, protein tyrosine kinase (PTK) can be divided into receptor protein tyrosine kinases (RTKs) and non-receptor protein tyrosine kinases (nrPTKs) according to their structure. ${ }^{18}$

RTKs usually consist of an extracellular domain, a transmembrane region, and an intracellular kinase domain. They are not only cell surface receptors for many growth factors and cytokines but also catalyze the phosphorylation of tyrosine residues of their target proteins. ${ }^{19}$ Uncontrolled RTK signals lead to cell growth disorders and cancer, which provided the rationale for the development of strategies for the prevention and interception of RTK signaling as a way to treat cancer. A number of RTKs have been shown to be associated with VS, such as ErbB, platelet-derived growth factor (PDGF), fibroblasts growth factor (FGF), insulin-like growth factor-1 
(IGF-1), and vascular endothelial growth factor (VEGF). ${ }^{20-25}$

Additionally, nrPTKs, including Src, BCR-ABL, and the JAK/STAT pathway, are not receptors per se. They generally do not have an extracellular domain, but are coupled to the cell membrane or exist in the cytoplasm, and their tyrosine kinase activity can be activated after binding to the activated receptor. ${ }^{26}$ The activation of nrPTKs and downstream signal transduction pathways can promote cell proliferation, cell apoptosis resistance, and oncogenesis. Further, over-activation of the Src pathway has been found in $N F 2 .^{27}$

\section{ErbB Family Protein Inhibitors}

The ErbB family's cell membrane receptors include EGFR (HER1/erbB-1), HER2 (neu/erbB-2), HER3 (erbB-3), and HER4 (erbB-4). When specific ligands bind to the extracellular domain, they induce a conformational change in the transmembrane region, causing ErbB family members to form heterodimers and simultaneously activate the intracellular kinase domain. ${ }^{28}$ Activation of ErbB receptors was considered a common feature of both sporadic and NF2-related VS, and EGFR expression levels correlated directly with VS tumor size and inversely with patient age. $^{29,30}$ Besides, an intriguing finding is that EGF was upregulated in all NF2-related VS, but not so in any of the sporadic VS. ${ }^{29}$ Moreover, NF2-related VS tend to present in young patients experiencing a growth phase with greater levels of circulating EGF, implying that an EGFR inhibitor might have greater efficacy in $N F 2$ patients.

The predominant ErbB receptor dimerization pattern in VS is EGFR and ErbB2 heterodimers. ${ }^{31}$ Trastuzumab, a humanized anti-ErbB2 monoclonal antibody, can significantly reduce VS cells' proliferation and VS xenografts' growth; however, this antibody does not ensure a significant increase in VS cells' death. ${ }^{32}$

Lapatinib is a potent and reversible tyrosine kinase inhibitor that has been widely used in the treatment of metastatic breast cancer. ${ }^{33}$ It has a dual inhibitory effect on EGF activation of EGFR/ErbB2, thus, it may be effective at abrogating the growth effects of EGF in VS In a preclinical VS model, molecular targeted therapy with lapatinib can inhibit ErbB2 phosphorylation and survivin upregulation. $^{30}$ A Phase II study showed that lapatinib carries minor toxicity and has the effect of reducing tumor volume and improving hearing in NF2 patients with progressive $\mathrm{VS}^{34}$
Additionally, another study demonstrated that lapatinib is less potent for inhibiting the proliferation of schwannoma cells, compared with erlotinib, which may be due to the upregulation of ErbB3 that is caused by lapatinib's inhibition of ErbB2. ${ }^{35,36}$ Erlotinib is a reversible, small molecule EGFR-specific tyrosine kinase inhibitor. It can significantly reduce the growth of VS xenografts in nude mice and increase cell death. ${ }^{32}$ However, an erlotinib strategy in $11 N F 2$-related VS was found to be clinically ineffective for tumor size reduction and improving hearing responses. $^{37}$

\section{PDGFR Family Protein Inhibitor}

The PDGFR family includes PDGFR- $\alpha$, PDGFR- $\beta$, colony-stimulating factor1-receptor (CSF1-R), fetal liver kinase-2 (Flk-2), and c-kit. Compared with normal nerves, the expression and activation of c-kit, PDGFR- $\alpha$ and PDGFR- $\beta$ in sporadic and NF2-related VS are all increased. $^{38}$ Therefore, they are all candidates as VS therapeutic targets. Imatinib mesylate (STI571) is an inhibitor of the BCR-ABL fusion kinase designed to treat chronic myelogenous leukemia (CML). In vitro studies using the immortalized NF2-null VS cell line HEI-193 showed that imatinib mesylate inhibits the activation of c-KIT, PDGFR- $\alpha$, and PDGFR- $\beta$ and its downstream signaling pathways, leading to increased apoptosis, cell cycle arrest, and decreased cell viability in a dose-dependent manner $\left(\mathrm{IC}_{50} 5-10 \mu \mathrm{mol} / \mathrm{L}\right){ }^{21,38}$ Moreover, corneal angiogenesis assay revealed that imatinib has an inhibitory effect for angiogenesis in both sporadic and NF2-related VS. ${ }^{39}$ This dual inhibition of tumorigenesis and angiogenesis potentializes imatinib in the treatment of VS.

Nilotinib (AMN107) is a second-generation RTK inhibitor with a target profile similar to that of imatinib, but has increased potency, decreased toxicity, and greater tissue permeability, making it easier to penetrate the bloodbrain barrier. ${ }^{40}$ Nilotinib is currently used to treat imatinibresistant CML and Philadelphia chromosome-positive acute lymphoblastic leukemia ( $\mathrm{Ph}+\mathrm{ALL})$. Nilotinib has been shown to inhibit cell proliferation more effectively than imatinib in a primary human schwannoma cell in vitro model, indicating that this compound has a therapeutic effect on merlin-deficient tumors. ${ }^{41}$ In HEI193 cells, nilotinib can reduce cell viability, inhibit proliferation and increase apoptosis; these anti-tumorigenic effects are related to the inhibition of PDGFR- $\alpha$ and PDGFR- $\beta$, as well as their downstream signaling mediators, Akt and mTOR. ${ }^{42}$ 
Ponatinib (AP24534) is a third-generation inhibitor of $\mathrm{BCR} / \mathrm{ABL}$ tyrosine kinase that is considered as a pan-BCR -ABL inhibitor with potent anti-tumorigenic properties in other cancers. ${ }^{43}$ Alejandra et al observed that ponatinib can reduce cell viability of primary VS cells with $N F 2$ mutations and stimulate a robust G1 cell cycle arrest of merlin-deficient human Schwann cells (HSC) by decreasing the highly phosphorylated PDGFR $\alpha / \beta$ in merlindeficient HSC and VS samples. Therefore, ponatinib might have significant therapeutic value for VS. ${ }^{44}$

\section{VEGFR Inhibitor}

The VEGFR family mainly includes VEGFR-1 (Flt-1), VEGFR-2 (Flk-1/KDR), and VEGFR-3 (Flt-4), which are important regulators of physiological or pathological angiogenesis. Merlin deletion can lead to downregulation of the protein semaphoring3F (SEMA3F) that inhibits VEGF-mediated angiogenesis. ${ }^{45,46}$ Studies have shown that the concentration of VEGF and VEGFR-1 is related to the growth rate of VS, which warrants further research regarding the anti-VEGF monoclonal antibody bevacizumab for VS treatment. ${ }^{47}$ In 2009, Plotkin reported that, for patients with $N F 2$ and progressive VSs, bevacizumab $(5 \mathrm{mg} / \mathrm{kg} / 2$ week) treatment can lead to tumor shrinkage in up to $90 \%$ of cases patients, as well as durable hearing response in over half of cases. ${ }^{48}$ Subsequently, a variety of studies validated that bevacizumab can benefit progressive NF2-VS patients in terms of hearing improvement and tumor-volume reduction. ${ }^{49-52}$ Although bevacizumab has achieved promising and satisfactory results in progressive and large tumors, its therapeutic effect seems to have population differences. First, its efficacy in pediatric NF2-VS patients is quite controversial. A previous study showed that the average annual tumor growth rate in children (median age at inclusion was 15 years) was reduced from $138 \%$ to $36 \%$ after one year of treatment. ${ }^{53}$ However, follow-up studies have revealed that although bevacizumab can delay pediatric patients' hearing loss, it has minimal effect on objective radiological response compared with adult participants. ${ }^{50,52,54}$ Second, bevacizumab did not cause tumor residuals regression or hearing improvement in any of the 9 young NF2-VS patients after partial resection, indicating this pharmacotherapy might have poorer efficacy in smaller and slowgrowth tumors, thus, new treatment strategies are required. ${ }^{55}$

The DCE-MRI data suggested bevacizumab can normalize the function of tumor vessels and potentially restore the normality of the blood-nerve barrier, while also improving vascular perfusion and oxygen delivery, thereby reducing tumor edema and enhancing the efficacy of radiotherapy. ${ }^{48,56}$ The volumetric response to bevacizumab therapy can be predicted by the mean apparent diffusion coefficient at baseline, while hearing improvement is inversely correlated with the baseline plasma hepatocyte growth factor (HGF) level. ${ }^{48,57}$

Compared with malignancies, the medication time of bevacizumab in the treatment of benign tumors is usually prolonged, making drug tolerability an issue to consider. The main causes for bevacizumab adverse reactions are intravenous route of administration and dose accumulation. A retrospective study showed that for $33 N F 2$-related VS or ependymoma patients treated with bevacizumab $(5 \mathrm{mg} / \mathrm{kg}$ biweekly, IV), 58\% developed hypertension and $62 \%$ developed proteinuria, implying an urgency to find an optimal dosing schedule. ${ }^{58}$ The super-selective intra-arterial infusion of bevacizumab, after temporary disruption of the bloodbrain barrier, was capable of improving drug concentrations at the tumor site, leading to better therapeutic effect in NF2VS patients. ${ }^{59}$ By reducing the dose of bevacizumab from $5 \mathrm{mg} / \mathrm{kg}$ biweekly to $2.5 \mathrm{mg} / \mathrm{kg}$ bi- or tri-weekly, the adverse effects of hypertension or proteinuria in three $N F 2$-VS patients disappeared with sustained clinical response, indicating that the low-dose regimen is more desirable in the long-term treatment with bevacizumab. ${ }^{60}$

The role of bevacizumab in NF2-VS has been well documented. An adult female patient with progressive sporadic VS also exhibited excellent imaging response to bevacizumab, providing a new treatment alternative for sporadic VS patients who are not suitable for standard treatment. ${ }^{61}$ The safety and preliminary efficacy of the VEGFRs peptide vaccine demonstrated in NF2 patients promises a new hope for the immunotherapy of NF2-VS. ${ }^{62}$

\section{HGFR Inhibitor}

The hepatocyte growth factor (HGF) receptor, also known as c-MET (c-mesenchymal-epithelial transition) is a glycosylated receptor tyrosine kinase that expressed on the cell surface and plays a central role in driving tumorigenesis. ${ }^{63}$ Numerous studies have shown that the over-activation of c-MET may initiate the transformation of normal cells into tumor cells, and further drive subsequent events such as invasion and metastasis. The activation of the HGF/c-MET pathway in sporadic VS can mobilize the inflammation network in the brain microenvironment and promote the progression of cancer. ${ }^{64,65}$ This 
pathway can also protect cells from DNA fragmentation and apoptosis induced by chemotherapy or radiotherapy through PI3K/Akt signaling, and is related to the resistance of radiotherapy, chemotherapy and targeted therapy. ${ }^{66-68}$

The c-MET and anaplastic lymphoma kinase inhibitor crizotinib (CRZ, PF-02341066) can enhance radiationinduced DNA damage of NF2 schwannoma cells, thereby enhancing tumors' radio-sensitivity, which is conducive to reducing the dose of radiotherapy and protecting patients' hearing. ${ }^{69}$ The study in animal models of NF2 delineate the potential target of $\mathrm{CRZ}$ is focal adhesion kinase 1 (FAK1), with inhibition of this target can suppress tumorigenesis and rescue the treatment effects of the CRZresistant forms of FAK $1{ }^{70}$ A Phase II clinical trial of CRZ for NF2 and progressive VS in children and adults is ongoing (NCT04283669). Simultaneous use of the c-MET inhibitor cabozantinib and the Src inhibitor saracatinib can cause caspase-dependent apoptosis in merlindeficient mouse Schwann cells (MD-MSC) and reduce the viability of human VS cells with $N F 2$ mutation by $40 \%$, which is more effective than using either inhibitor alone. ${ }^{71}$

There is a crosstalk between c-MET and VEGFA in VS, as described in other pathological types of cells. Using c-MET-targeted siRNA, Sonam et al found that c-MET and VEGFA protein levels decreased, while VEGFAtargeted siRNA reduced c-MET expression; this discovery highlights combined inhibition of VEGFA and c-MET as an effective pharmacotherapy. ${ }^{64}$

\section{Small Molecule Inhibitors of Akt Signal Transduction}

A better understanding of the underlying mechanisms of VS tumorigenesis can help design new targeted therapies. The most studied abnormality in VS is the PI3K/Akt pathway, which is manifested by elevated Akt mRNA and protein levels, as well as higher Akt phosphorylation levels in VS samples. ${ }^{72,73}$ Because the PI3K/Akt pathway is the confluence point of many growth stimuli and controls cellular processes and responses (such as cell survival, cell proliferation, insulin response, stress response and differentiation) through its downstream substrates, its activation may contribute to tumorigenesis. ${ }^{74}$ Therefore, the $\mathrm{PI} 3 \mathrm{~K} /$ Akt pathway is the most attractive therapeutic target for VS, and small molecule inhibitors of Akt signaling may have therapeutic potential to inhibit the growth of benign VS and malignant schwannomas.
OSU-03012 (AR-12) is a phosphoinositidedependent kinase-1 (PDK1) inhibitor that can induce apoptosis of several types of cancer cells. Although OSU-03012 is a novel derivative of the cyclooxygenase 2 (COX-2, also known as prostaglandin $\mathrm{G} / \mathrm{H}$ synthase 2, PTGS2) inhibitor celecoxib (Celebrex $\left.{ }^{\mathrm{TM}}\right)$, it has no COX-2 inhibitory activity. By dose-dependent reduction of Akt phosphorylation in VS cells, OSU-03012 inhibits VS cell growth and promotes apoptosis. ${ }^{75}$

Additionally, OSU-HDAC42 (AR-42), a novel phenylbutyrate-derived histone deacetylase inhibitors (HDACIs), can inhibit the downstream Akt expression of PI3K and PDK1 through protein phosphatase1-mediated Akt dephosphorylation, showing the effect of G2 cell cycle arrest and VS cell apoptosis induction in both cell and animal experiments. ${ }^{76}$ Further, an in vitro study demonstrated that AR-42 potently inhibits primary VS cell growth $\left(\mathrm{IC}_{50} \approx 500 \mathrm{nM}\right)$ at doses correlating with Akt pathway inhibition, which indicates that AR-42 could be a promising molecular targeted agent for $\mathrm{VS}^{77}$

\section{mTORCI Inhibitor}

mTOR is a downstream signal of the PI3K/Akt pathway that can integrate signals from multiple upstream pathways as well as the local intracellular environment and serve as a hub in the intracellular communication cascade. Merlin was reported to negatively regulate mTORC1, inhibition of the constitutive activated mTORC1 pathway in merlindeficient tumors may be a useful targeted therapy for VS. ${ }^{17}$

Using the mTORC1 inhibitor rapamycin (also known as sirolimus) to treat merlin-deficient schwannoma cell lines, allogeneic NF2-/- mice models, and genetically engineered mouse models of NF2 schwannomas, previous studies have found that rapamycin are cytostatic for NF2-/schwannoma cells, and that it can also inhibit the growth of merlin-deficient tumors in vivo. Consistent with this, rapamycin can lead to tumor volume reduction in $N F 2$ patients with growing $\mathrm{VS}^{78}$

Everolimus (RAD001), a derivative of rapamycin, can not only inhibit mTORC1 but also reduce tumor angiogenesis. ${ }^{79}$ Although a phase II study found that everolimus was ineffective in progressive $N F 2$-related VS patients, another study showed that taking everolimus reduced the median annual tumor growth rate in 55.6\% of patients with $N F 2$-related VS, from $67 \%$ before treatment to $0.5 \%$ during treatment. ${ }^{80,81}$ 


\section{Chemokine Receptor-4 (CXCR4)} Inhibitor

CXCR4 is a $\mathrm{G}$ protein-coupled receptor of the chemokine receptor subfamily, with a molecular weight of $40 \mathrm{kDa}$. It plays an important role in the development of the nervous, hematopoietic, and cardiovascular systems during embryogenesis, and in pathological processes like infection and tumor development. ${ }^{82,83}$ CXCR4 is also considered to be correlated with the tumorigenesis and functional impairment of sporadic and NF2-related VS. ${ }^{84}$

CXCR4-directed positron emission tomography/computed tomography (PET/CT) imaging with radiolabeled CXCR4-targeted ligand [68Ga] Pentixafor in VS patients can be used to evaluate CXCR4 expression in VS patients. ${ }^{85}$ These results provide a possibility for the use of Plerixafor (AMD3100), a CXCR4-targeting drug, in individualized therapeutic tactics of VS patients.

\section{Inflammatory Factor Inhibitors COX2 Inhibitor}

Several studies have shown that the expression of COX-2 is associated with sporadic and NF2-related VS proliferation. ${ }^{86,87}$ Mutations in the $N F 2$ gene can activate the Hippo pathway, in which the effector molecule YAP can promote the transcription of the key enzyme COX-2 for prostaglandin biosynthesis. Prostaglandin E2 (PGE2) catalyzed by COX-2 has multiple roles in cell proliferation, apoptosis, angiogenesis, inflammation, and immune monitoring. ${ }^{88}$ This suggests that COX-2 inhibitors may have the potential to inhibit the growth of VS A significant negative correlation between aspirin users and sporadic VS growth has been found, indicating the potential therapeutic role of aspirin in sporadic VS management. ${ }^{89}$

However, other studies on celecoxib, aspirin, and COX-2 inhibitors in non-steroidal anti-inflammatory drugs (NSAIDs), found that there is no expected growth inhibitory effect for celecoxib on $N F 2$ or aspirin on VS. ${ }^{90-92}$ Other studies have shown that NSAIDs, glucocorticoids, or other immunosuppressive drugs could not alter the expression of COX-2 in VS, and that NSAIDs were not significantly correlated with VS growth, tumor diameter, and average VS growth rate. ${ }^{92-94}$

In addition to inhibiting COX-2, aspirin can also suppress the activated NF- $\mathrm{KB}$ pathway in VS, which is another potential mechanism of the therapeutic effect of aspirin. ${ }^{95,96}$ Aspirin is recommended by the Congress of
Neurosurgeons for "wait and scan" VS patients to prevent tumor proliferation. ${ }^{97}$

\section{NF-KB Inhibitor}

Mifepristone (RU486) is a progesterone and glucocorticoid receptor antagonist used for medical abortion. It is well tolerated via oral administration and can be used for the palliative treatment of glioblastoma multiforme. ${ }^{98,99}$ The screening by computational drug repositioning platform ksRepo found that mifepristone has the potential to treat VS. Moreover, Ingenuity Pathway Analysis (IPA) results infer that mifepristone acts on the upstream of VS inflammation markers, such as NF- $\kappa \mathrm{B} .{ }^{100}$ Further cell experiments demonstrated that mifepristone inhibited the metabolic and proliferative activity of VS cells in a dosedependent manner, and this effect was independent of whether the NF2 gene was mutated. ${ }^{101}$

\section{Discussion}

For a long time, the unpredictable course of VS has presented unique management challenges. Currently, local treatment is the main option for VS, and there is no level I evidence to support systematic treatment of VS. In addition to the aforementioned drugs, the inhibitory effects of $\mathrm{LiCl}$, cucurbitine D and Goyazensolide on the proliferation of NF2 deficient schwannoma cells, tanshinone IIA, and Ailanthone on the proliferation of VS cells have been confirmed. ${ }^{102-105}$ The delivery of tumor necrosis factor (TNF)-targeted siRNA by nanoparticles can reduce the VS- sensorineural hearing loss-related protein concentration. ${ }^{106}$ The use of the NF2-VS growth model based on the early tumor volume dynamics and the VS growth model when treated with bevacizumab and everolimus alone or in combination, established by Ouerdani et al, opens up the prospect of individualized treatment for NF2 patients. $^{107}$

The research on the pathways in which the NF2 gene product interacts provides a pharmacological basis for the development of VS targeted drugs. Compared with traditional chemotherapy, targeted therapy possesses less vascular nerve damage and has good application prospects. NF2 gene mutation and merlin dysfunction is a typical characteristic of NF2-VS and often occurs in sporadic VS.,3 Therefore, drugs based on this mechanism have the potential to treat both NF2-VS and sporadic VS As we summarized, imatinib mesylate, bevacizumab, and aspirin have shown efficacy in sporadic VS, suggesting the potential of targeted therapy in sporadic VS. ${ }^{39,61,89}$ The loss of merlin results in 
Table I Summary of Drugs Under Research

\begin{tabular}{|c|c|c|c|c|}
\hline Class & $\begin{array}{l}\text { Therapeutic } \\
\text { Target }\end{array}$ & Drug & Features & Ref \\
\hline \multirow[t]{10}{*}{ PTK inhibitors } & \multirow[t]{3}{*}{ ErbB } & Trastuzumab & Inhibit cells proliferation without significant increase in VS cells death. & [32] \\
\hline & & Lapatinib & $\begin{array}{l}\text { Reduce tumor volume and improve hearing in NF2-VS patients in a phase II } \\
\text { study. }\end{array}$ & [34] \\
\hline & & Erlotinib & $\begin{array}{l}\text { Can inhibit the growth of VS and increase cell death in nude mice, but ineffective } \\
\text { in NF2-VS patients. }\end{array}$ & {$[32,37]$} \\
\hline & \multirow[t]{3}{*}{ PDGFR } & $\begin{array}{l}\text { Imatinib } \\
\text { mesylate }\end{array}$ & $\begin{array}{l}\text { Increased apoptosis and decrease cell viability in a dose-dependent manner in } \\
\text { HEI- } 193 \text { cell line. Imatinib also has an angiogenesis inhibitory effect in both the } \\
\text { sporadic and NF2-VS by corneal angiogenesis assay. }\end{array}$ & {$[21,38,39]$} \\
\hline & & Nilotinib & Inhibit proliferation and increase apoptosis in HEI-193 cell line. & {$[42]$} \\
\hline & & Ponatinib & $\begin{array}{l}\text { Reduce cell viability of primary NF2-VS cells and induce GI cell cycle arrest of } \\
\text { merlin-deficient HSC. }\end{array}$ & [44] \\
\hline & VEGFR & Bevacizumab & $\begin{array}{l}\text { Benefit NF2-VS patients in hearing improvement and tumor shrinkage. } \\
\text { A sporadic case of imaging reaction to bevacizumab was also reported. }\end{array}$ & {$[48-52,61]$} \\
\hline & \multirow[t]{3}{*}{ HGFR } & Crizotinib & $\begin{array}{l}\text { Enhance radiosensitivity of NF2 schwannoma cells, a phase II clinical trial in } \\
\text { progressive VS patients is ongoing. }\end{array}$ & [69] \\
\hline & & Cabozantinib & Combination with Src inhibitor saracatinib can reduce NF2-VS cell viability. & {$[7 I]$} \\
\hline & & $\begin{array}{l}\text { c-MET } \\
\text { targeted } \\
\text { siRNA }\end{array}$ & Decrease both c-MET and VEGFA protein levels. & {$[64]$} \\
\hline \multirow[t]{2}{*}{ Akt inhibitors } & \multirow[t]{2}{*}{ Akt } & OSU-030I2 & Inhibit cells proliferation and promote apoptosis. & {$[75]$} \\
\hline & & $\begin{array}{l}\text { OSU- } \\
\text { HDAC42 }\end{array}$ & $\begin{array}{l}\text { Induce G2 cell cycle arrest and VS cell apoptosis in both in vitro and in vivo } \\
\text { study. }\end{array}$ & {$[76,77]$} \\
\hline \multirow{2}{*}{$\begin{array}{l}\text { mTORCI } \\
\text { inhibitors }\end{array}$} & \multirow[t]{2}{*}{ mTORCI } & Rapamycin & Result in tumor volume reduction in NF2-VS patients. & [78] \\
\hline & & Everolimus & $\begin{array}{l}\text { One study believes that everolimus is ineffective in NF2-VS, but in another study, } \\
\text { it can reduce the median annual tumor growth rate in NF2-VS patients }\end{array}$ & {$[80,81]$} \\
\hline $\begin{array}{l}\text { CXCR-4 } \\
\text { inhibitors }\end{array}$ & CXCR-4 & $\begin{array}{l}\text { CXCR4 } \\
\text { inhibitor }\end{array}$ & I & {$[84]$} \\
\hline \multirow[t]{3}{*}{$\begin{array}{l}\text { Inflammatory } \\
\text { factor } \\
\text { inhibitors }\end{array}$} & \multirow[t]{2}{*}{$\operatorname{cox} 2$} & Aspirin & $\begin{array}{l}\text { A study confirmed an inverse correlation between aspirin users and sporadic VS } \\
\text { growth, but another study suggested aspirin had no expected growth inhibitory } \\
\text { on VS patients. }\end{array}$ & {$[89,92]$} \\
\hline & & Celecoxib & No expected growth inhibitory on genetically engineered murine model of NF2. & [91] \\
\hline & $\mathrm{NF}-\kappa \mathrm{B}$ & Mifepristone & Inhibit the metabolism and proliferation activity of VS cells. & {$[101]$} \\
\hline
\end{tabular}

the activation of a variety of signals related to cell survival, growth, and proliferation, and these abnormally expressed molecules are also potential drug therapeutic targets, of which VEGF has made the most progress. ${ }^{108}$ Table 1 shows the major categories of drugs currently in development. The complex interlinked signaling pathways in the pathogenesis of VS suggest that a combination therapy may provide an ideal therapeutic effect. Besides, due to the long duration of VS, the potential adverse reactions and toxicity of long-term use of the drug should also be considered.

\section{Conclusions}

Targeted therapy has shown efficacy in both sporadic VS and NF2-VS. Widely accepted treatment options, 
including long-term observation, surgery, and radiation therapy, plus targeted therapies currently under research, are tailored for patients with different tumor characteristics. Further multidisciplinary cooperation will help to choose the best treatment plan for individual patients and maximize the protection of nerve function.

\section{Abbreviations}

ATP, adenosine triphosphate; c-MET, c-mesenchymalepithelial transition; CML, chronic myelogenous leukemia; COX2, cyclooxygenase 2; CSF1-R, colony-stimulating factor1-receptor; CXCR4, chemokine receptor-4; ERK, extracellular-signal-regulated kinases; FAK1, focal adhesion kinase 1; FGF, fibroblasts growth factor; Flk-2, fetal liver kinase-2; HDACIs, histone deacetylase inhibitors; HGF, hepatocyte growth factor; HSC, human Schwann cell; IGF1, insulin-like growth factor-1; IPA, Ingenuity Pathway Analysis; MD-MSC, merlin-deficient mouse Schwann cells; MEK, mitogen extracellular signal-regulated kinase; mTORC1, mammalian target of rapamycin complex 1 ; $N F 2$, neurofibromatosis type 2; nrPTKs, non-receptor protein tyrosine kinases; NSAIDs, non-steroidal anti-inflammatory drugs; PAK, p21-activated kinase; PDGF, platelet-derived growth factor; PDK1, phosphoinositide-dependent kinase1; PET/CT, positron emission tomography/computed tomography; PGE2, prostaglandin E2; Ph+ ALL, Philadelphia chromosome-positive acute lymphoblastic leukemia; PI3K, phosphoinositide 3-kinase; PTGS2, prostaglandin $\mathrm{G} / \mathrm{H}$ synthase 2; PTK, protein tyrosine kinase; Raf, rapidly accelerated fibrosarcoma; Ras, retrovirus-associated DNA sequences; RTKs, receptor protein tyrosine kinases; SEMA3F, semaphoring3F; TNF, tumor necrosis factor; VEGF, vascular endothelial growth factor; VSs, vestibular schwannomas.

\section{Acknowledgments}

This study was Sponsored by Shanghai Sailing Program (19YF1405700), National Natural Science Foundation of China (NSFC81872938, 82003864).

\section{Disclosure}

The authors report no conflicts of interest in this work.

\section{References}

1. Huang X, Xu J, Xu M, et al. Clinical features of intracranial vestibular schwannomas. Oncol Lett. 2013;5(1):57-62. doi:10.3892/ol.2012.1011
2. Asthagiri AR, Parry DM, Butman JA, et al. Neurofibromatosis type 2. Lancet. 2009;373(9679):1974-1986. doi:10.1016/s01406736(09)60259-2

3. Lee JD, Kwon TJ, Kim UK, Lee WS. Genetic and epigenetic alterations of the $N F 2$ gene in sporadic vestibular schwannomas. PLoS One. 2012;7(1):5. doi:10.1371/journal.pone.0030418

4. Suryanarayanan R, Ramsden RT, Saeed SR, et al. Vestibular schwannoma: role of conservative management. J Laryngol Otol. 2010;124(3):251-257. doi:10.1017/s0022215109992362

5. Van Linge A, Van Os R, Hoekstra N, et al. Progression of hearing loss after LINAC-based stereotactic radiotherapy for vestibular schwannoma is associated with cochlear dose, not with pre-treatment hearing level. Radiat Oncol. 2018;13(1):253. doi:10.1186/s13014-018-1202-z

6. Wise SC, Carlson ML, Tveiten OV, et al. Surgical salvage of recurrent vestibular schwannoma following prior stereotactic radiosurgery. Laryngoscope. 2016;126(11):2580-2586. doi:10.1002/lary.25943

7. Hayhurst C, Zadeh G. Tumor pseudoprogression following radiosurgery for vestibular schwannoma. Neuro-Oncology. 2012;14 (1):87-92. doi:10.1093/neuonc/nor171

8. Sobel RA. Vestibular (acoustic) schwannomas: histologic features in neurofibromatosis 2 and in unilateral cases. J Neuropathol Exp Neurol. 1993;52(2):106-113. doi:10.1097/00005072-19930300000002

9. Jaaskelainen J, Paetau A, Pyykko I, et al. Interface between the facial nerve and large acoustic neurinomas. Immunohistochemical study of the cleavage plane in NF2 and non-NF2 cases. J Neurosurg. 1994;80(3):541-547. doi:10.3171/ jns.1994.80.3.0541

10. Gilkes CE, Evans DG. Review of radiation therapy services for neurofibromatosis (NF2) patients in England. Br J Neurosurg. 2014;28(1):16-19. doi:10.3109/02688697.2013.861386

11. McClatchey AI. Membrane organization and tumorigenesis-the NF2 tumor suppressor, Merlin. Genes Dev. 2005;19 (19):2265-2277. doi:10.1101/gad.1335605

12. Yi CL, Troutman S, Fera D, et al. A tight junction-associated merlin-angiomotin complex mediates merlin's regulation of mitogenic signaling and tumor suppressive functions. Cancer Cell. 2011;19(4):527-540. doi:10.1016/j.ccr.2011.02.017

13. Xiao GH, Beeser A, Chernoff J, Testa JR. p21-activated kinase links Rac/Cdc42 signaling to merlin. J Biol Chem. 2002;277 (2):883-886. doi:10.1074/jbc.C100553200

14. Okada M, Wang YR, Jang SW, et al. Akt phosphorylation of merlin enhances its binding to phosphatidylinositols and inhibits the tumor-suppressive activities of merlin. Cancer Res. 2009;69 (9):4043-4051. doi:10.1158/0008-5472.can-08-3931

15. Jacob A, Lee TX, Neff BA, et al. Phosphatidylinositol 3-kinase/ Akt pathway activation in human vestibular schwannoma. Otol Neurotol. 2008;29(1):58-68. doi:10.1097/ mao.0b013e31816021f7

16. Li W, Cooper J, Zhou L, et al. Merlin/NF2 loss-driven tumorigenesis linked to CRL4(DCAF1)-mediated inhibition of the hippo pathway kinases Lats1 and 2 in the nucleus. Cancer Cell. 2014;26 (1):48-60. doi:10.1016/j.ccr.2014.05.001

17. James MF, Stivison E, Beauchamp R, et al. Regulation of mTOR complex 2 signaling in neurofibromatosis 2-deficient target cell types. Mol Cancer Res. 2012;10(5):649-659. doi:10.1158/15417786.Mcr-11-0425-t

18. Robinson DR, Wu YM, Lin SF. The protein tyrosine kinase family of the human genome. Oncogene. 2000;19 (49):5548-5557. doi:10.1038/sj.onc. 1203957

19. Kazlauskas A. Receptor tyrosine kinases and their target. Curr Opin Genet Dev. 1994;4(1):5-14. doi:10.1016/0959-437x(94) 90085-x 
20. Wickremesekera A, Hovens CM, Kaye AH. Expression of ErbB-1 and 2 in vestibular schwannomas. J Clin Neurosci. 2007;14 (12):1199-1206. doi:10.1016/j.jocn.2007.05.009

21. Altuna X, Lopez JP, Yu MA, et al. Potential role of imatinib mesylate (gleevec, STI-571) in the treatment of vestibular schwannoma. Otol Neurotol. 2011;32(1):163-170. doi:10.1097/ MAO.0b013e3182009665

22. Blair KJ, Kiang A, Wang-Rodriguez J, et al. EGF and bFGF promote invasion that is modulated by PI3/akt kinase and erk in vestibular schwannoma. Otol Neurotol. 2011;32(2):308-314. doi:10.1097/MAO.0b013e318206fc3d

23. Dilwali S, Lysaght A, Roberts D, et al. Sporadic vestibular schwannomas associated with good hearing secrete higher levels of fibroblast growth factor 2 than those associated with poor hearing irrespective of tumor size. Otol Neurotol. 2013;34 (4):748-754. doi:10.1097/MAO.0b013e31828048ec

24. Fotakopoulos G, Fountas K, Tsianaka E, et al. Could IGF-I levels play a neuroprotective role in patients with large vestibular schwannomas? Future Sci OA. 2018;4(2):9. doi:10.4155/fsoa-2017-0103

25. Taurone S, Bianchi E, Attanasio G, et al. Immunohistochemical profile of cytokines and growth factors expressed in vestibular schwannoma and in normal vestibular nerve tissue. Mol Med Rep. 2015;12(1):737-745. doi:10.3892/mmr.2015.3415

26. Tsygankov AY. Non-receptor protein tyrosine kinases. Front Biosci. 2003;8(6):S595-S635. doi:10.2741/1106

27. Zhou L, Ercolano E, Ammoun S, et al. Merlin-deficient human tumors show loss of contact inhibition and activation of Wnt/ beta-catenin signaling linked to the PDGFR/Src and Rac/PAK pathways. Neoplasia. 2011;13(12):1101-U17. doi:10.1593/ neo. 111060

28. Linggi B, Carpenter G. ErbB receptors: new insights on mechanisms and biology. Trends Cell Biol. 2006;16(12):649-656. doi:10.1016/j.tcb.2006.10.008

29. Doherty JK, Ongkeko W, Crawley B, Andalibi A, Ryan AF. ErbB and Nrg: potential molecular targets for vestibular schwannoma pharmacotherapy. Otol Neurotol. 2008;29(1):50-57. doi:10.1097/ mao.0b013e31815d4429

30. Sylwia A, Cunliffe $\mathrm{CH}$, Allen JC, et al. ErbB/HER receptor activation and preclinical efficacy of lapatinib in vestibular schwannoma. Neuro Oncol. 2010;12(8):834-843. doi:10.1093/ neuonc/noq012

31. Ahmad ZK, Brown CM, Cueva RA, Ryan AF, Doherty JK. ErbB expression, activation, and inhibition with lapatinib and tyrphostin (AG825) in human vestibular schwannomas. Otol Neurotol. 2011;32(5):841-847. doi:10.1097/MAO.0b013e31821f7d88

32. Clark JJ, Provenzano M, Diggelmann HR, et al. The ErbB inhibitors trastuzumab and erlotinib inhibit growth of vestibular schwannoma xenografts in nude mice: a preliminary study. Otol Neurotol. 2008;29(6):846-853. doi:10.1097/MAO.0b013e31817f7398

33. Guarneri V, Generali DG, Frassoldati A, et al. Double-blind, placebo-controlled, multicenter, randomized, phase IIb neoadjuvant study of letrozole-lapatinib in postmenopausal hormone receptor-positive, human epidermal growth factor receptor 2-negative, operable breast cancer. J Clin Oncol. 2014;32 (10):1050-1057. doi:10.1200/jco.2013.51.4737.

34. Karajannis MA, Legault G, Hagiwara M, et al. Phase II trial of lapatinib in adult and pediatric patients with neurofibromatosis type 2 and progressive vestibular schwannomas. Neuro-Oncology. 2012;14(9):1163-1170. doi:10.1093/neuonc/nos 146

35. Bush ML, Burns SS, Oblinger J, et al. Treatment of vestibular schwannoma cells with ErbB inhibitors. Otol Neurotol. 2012;33 (2):244-257. doi:10.1097/MAO.0b013e31823e287f

36. Garrett JT, Olivares MG, Rinehart C, et al. Transcriptional and posttranslational up-regulation of HER3 (ErbB3) compensates for inhibition of the HER2 tyrosine kinase. Proc Natl Acad Sci U S A. 2011;108(12):5021-5026. doi:10.1073/pnas. 1016140108
37. Plotkin SR, Halpin C, Mckenna MJ, Loeffler JS, Barker FG, Barker FG. Erlotinib for progressive vestibular schwannoma in neurofibromatosis 2 patients. Otol Neurotol. 2010;31 (7):1135-1143. doi:10.1097/MAO.0b013e3181eb328a

38. Mukherjee J, Kamnasaran D, Balasubramaniam A, et al. Human schwannomas express activated platelet-derived growth factor receptors and c-kit and are growth inhibited by gleevec (imatinib mesylate). Cancer Res. 2009;69(12):5099-5107. doi:10.1158/ 0008-5472.Can-08-4475

39. Yener U, Avsar T, Akgun E, et al. Assessment of antiangiogenic effect of imatinib mesylate on vestibular schwannoma tumors using in vivo corneal angiogenesis assay laboratory investigation. J Neurosurg. 2012;117(4):697-704. doi:10.3171/2012.6.jns112263

40. Tanaka C, Yin OQP, Sethuraman V, et al. Clinical pharmacokinetics of the BCR-ABL tyrosine kinase inhibitor nilotinib. Clin Pharmacol Ther. 2010;87(2):197-203. doi:10.1038/clpt.2009.208

41. Ammoun S, Schmid MC, Triner J, Manley P, Hanemann CO. Nilotinib alone or in combination with selumetinib is a drug candidate for neurofibromatosis type 2. Neuro Oncol. 2011;13 (7):759-766. doi:10.1093/neuonc/nor056

42. Sabha N, Au K, Agnihotri S, et al. Investigation of the in vitro therapeutic efficacy of nilotinib in immortalized human NF2-null vestibular schwannoma cells. PLoS One. 2012;7(6):10. doi:10.1371/journal.pone.0039412

43. Tan FH, Putoczki TL, Stylli SS, Luwor RB. Ponatinib: a novel multi-tyrosine kinase inhibitor against human malignancies. Onco Targets Ther. 2019;12:635-645. doi:10.2147/ott.s189391

44. Petrilli AM, Garcia J, Bott M, et al. Ponatinib promotes a G(1) cell-cycle arrest of merlin/NF2-deficient human schwann cells. Oncotarget. 2017;8(19):31666-31681. doi:10.18632/ oncotarget.15912

45. Acevedo LM, Barillas S, Weis SM, Göthert JR, Cheresh DA. Semaphorin 3A suppresses VEGF-mediated angiogenesis yet acts as a vascular permeability factor. Blood. 2008;111(5):2674-2680. doi:10.1182/blood-2007-08-110205

46. Wong HK, Lahdenranta J, Kamoun WS, et al. Anti-vascular endothelial growth factor therapies as a novel therapeutic approach to treating neurofibromatosis-related tumors. Cancer Res. 2010;70(9):3483-3493. doi:10.1158/0008-5472.can-09-3107

47. Per C-T, Kim W, Amarnadh N, et al. VEGF and VEGF receptor-1 concentration in vestibular schwannoma homogenates correlates to tumor growth rate. Otol Neurotol. 2005;26(1):98-101. doi:10.1097/00129492-200501000-00017

48. Plotkin SR, Stemmer-Rachamimov AO, Barker FG, et al. Hearing improvement after bevacizumab in patients with neurofibromatosis type 2. New Eng J Med. 2009;361(4):358-367. doi:10.1056/ NEJMoa0902579

49. Plotkin SR, Merker VL, Halpin C, Jennings D, Barker FG. Bevacizumab for progressive vestibular schwannoma in neurofibromatosis type 2: a retrospective review of 31 patients. Otol Neurotol. 2012;33(6):1046-1052. doi:10.1097/MAO.0b013e31825e73f5

50. Morris KA, Golding JF, Axon PR, et al. Bevacizumab in neurofibromatosis type 2 (NF2) related vestibular schwannomas: a nationally coordinated approach to delivery and prospective evaluation. Neuro Oncol Pract. 2016;3(4):281-289. doi:10.1093/ nop/npv065

51. Alanin MC, Klausen C, Caye-Thomasen P, et al. The effect of bevacizumab on vestibular schwannoma tumour size and hearing in patients with neurofibromatosis type 2. Eur Arch Otorhinolaryngol. 2015;272(12):3627-3633. doi:10.1007/ s00405-014-3398-3

52. Plotkin SR, Duda DG, Muzikansky A, et al. Multicenter, prospective, phase ii and biomarker study of high-dose bevacizumab as induction therapy in patients with neurofibromatosis type 2 and progressive vestibular schwannoma. J Clin Oncol. 2019;37 (35):3446-3454. doi:10.1200/jco.19.01367 
53. Hochart A, Gaillard V, Baroncini M, et al. Bevacizumab decreases vestibular schwannomas growth rate in children and teenagers with neurofibromatosis type 2. J Neurooncol. 2015;124 (2):229-236. doi:10.1007/s11060-015-1828-8

54. Renzi S, Michaeli O, Salvador $\mathrm{H}$, et al. Bevacizumab for NF2-associated vestibular schwannomas of childhood and adolescence. Pediatr Blood Cancer. 2020;67(5):4. doi:10.1002/ pbc. 28228

55. Gugel I, Kluwe L, Zipfel J, et al. Minimal effect of bevacizumab treatment on residual vestibular schwannomas after partial resection in young neurofibromatosis type 2 patients. Cancers. 2019;11 (12):1862. doi: $10.3390 /$ cancers 11121862

56. Gao X, Zhao Y, Stemmer-Rachamimov AO, et al. Anti-VEGF treatment improves neurological function and augments radiation response in NF2 schwannoma model. Proc Natl Acad Sci U S A. 2015;112(47):14676-14681. doi:10.1073/pnas.1512570112

57. Blakeley JO, Ye X, Duda DG, et al. Efficacy and biomarker study of bevacizumab for hearing loss resulting from neurofibromatosis type 2-associated vestibular schwannomas. J Clin Oncol. 2016;34 (14):1669-1675. doi:10.1200/JCO.2015.64.3817

58. Slusarz KM, Merker VL, Muzikansky A, Francis SA, Plotkin SR. Long-term toxicity of bevacizumab therapy in neurofibromatosis 2 patients. Cancer Chemother Pharmacol. 2014;73 (6):1197-1204. doi:10.1007/s00280-014-2456-2

59. Riina HA, Burkhardt JK, Santillan A, et al. Short-term clinico-radiographic response to super-selective intra-arterial cerebral infusion of bevacizumab for the treatment of vestibular schwannomas in neurofibromatosis type 2. Interv Neuroradiol. 2012;18(2):127-132. doi:10.1177/159101991201800201

60. Said F, Philipp K, Carsten D, Alexander S, Victor-Felix M. Reduced dosage of bevacizumab in treatment of vestibular schwannomas in patients with neurofibromatosis type 2. Eur Arch Otorhinolaryngol. 2015;272(12):3857-3860. doi:10.1007/ s00405-015-3604-y

61. Karajannis MA, Hagiwara M, Schreyer M, Haque S. Sustained imaging response and hearing preservation with low-dose bevacizumab in sporadic vestibular schwannoma. Neuro-Oncology. 2019;21(6):822-824. doi:10.1093/neuonc/noz051

62. Tamura R, Fujioka M, Morimoto Y, et al. A VEGF receptor vaccine demonstrates preliminary efficacy in neurofibromatosis type 2. Nat Commun. 2019;10(1):5758. doi:10.1038/s41467-02016007-z

63. Konstorum A, Lowengrub JS. Activation of the HGF/c-Met axis in the tumor microenvironment: a multispecies model. $J$ Theor Biol. 2018;439:86-99. doi:10.1016/j.jtbi.2017.11.025

64. Sonam D, Daniel R, Stankovic KM. Interplay between VEGF-A and cMET signaling in human vestibular schwannomas and schwann cells. Cancer Biol Ther. 2015;16(1):170-175. doi:10.4161/15384047.2014.972765

65. Xing F, Liu Y, Sharma S, Wu K, Watabe K. Activation of the c-met pathway mobilizes an inflammatory network in the brain microenvironment to promote brain metastasis of breast cancer. Cancer Res. 2016;76(17):4970-4980. doi:10.1158/0008-5472.CAN-15-3541

66. Hu S-Y, Duan H-F, Li Q-F, et al. Hepatocyte growth factor protects endothelial cells against gamma ray irradiation-induced damage. Acta Pharmacol Sin. 2009;30(10):1415-1420. doi:10.1038/aps.2009.133

67. Medova M, Aebersold DM, Zimmer Y. MET inhibition in tumor cells by PHA665752 impairs homologous recombination repair of DNA double strand breaks. Int J Cancer. 2012;130(3):728-734. doi:10.1002/ijc. 26058

68. Delitto D, Vertes-George E, Hughes SJ, Behrns KE, Trevino JG. c-Met signaling in the development of tumorigenesis and chemoresistance: potential applications in pancreatic cancer. World $J$ Gastroenterol. 2014;20(26):8458-8470. doi:10.3748/wjg.v20. i26.8458
69. Zhao Y, Liu P, Zhang N, et al. Targeting the cMET pathway augments radiation response without adverse effect on hearing in NF2 schwannoma models. Proc Natl Acad Sci USA. 2018:201719966. doi:10.1073/pnas.1719966115.

70. Troutman S, Moleirinho S, Kota S, et al. Crizotinib inhibits NF2-associated schwannoma through inhibition of focal adhesion kinase 1. Oncotarget. 2016;7(34):54515-54525. doi:10.18632/ oncotarget. 10248

71. Fuse MA, Plati SK, Burns SS, et al. Combination therapy with c-met and src inhibitors induces caspase-dependent apoptosis of merlin-deficient schwann cells and suppresses growth of schwannoma cells. Mol Cancer Ther. 2017;16(11):2387-2398. doi:10.1158/1535-7163.mct-17-0417

72. Welling DB, Lasak JM, Akhmametyeva E, Ghaheri B, Chang LS. cDNA microarray analysis of vestibular schwannomas. Otol Neurotol. 2002;23(5):736-748. doi:10.1097/00129492200209000-00022

73. Lasak JM, Welling DB, Akhmametyeva EM, Salloum M, Chang LS. Retinoblastoma - cyclin-dependent kinase pathway deregulation in vestibular schwannomas. Laryngoscope. 2002;112 (9):1555-1561. doi:10.1097/00005537-200209000-00004

74. Lopiccolo J, Blumenthal GM, Bernstein WB, Dennis PA. Targeting the PI3K/Akt/mTOR pathway: effective combinations and clinical considerations. Drug Resist Updat. 2008;11(1-2):32-50. doi:10.1016/j.drup.2007.11.003

75. Lee TX, Packer MD, Huang J, et al. Growth inhibitory and anti-tumour activities of OSU-03012, a novel PDK-1 inhibitor, on vestibular schwannoma and malignant schwannoma cells. Eur J Cancer. 2009;45(9):1709-1720. doi:10.1016/j.ejca.2009.03.013

76. Bush ML, Oblinger J, Brendel V, et al. AR42, a novel histone deacetylase inhibitor, as a potential therapy for vestibular schwannomas and meningiomas. Neuro-Oncology. 2011;13(9):983-999. doi:10.1093/neuonc/nor072

77. Jacob A, Oblinger J, Bush ML, et al. Preclinical validation of AR42, a novel histone deacetylase inhibitor, as treatment for vestibular schwannomas. Laryngoscope. 2012;122(1):174-189. doi:10.1002/lary.22392

78. Giovannini M, Bonne NX, Vitte J, et al. mTORC1 inhibition delays growth of neurofibromatosis type 2 schwannoma. Neuro Oncol. 2014;16(4):493-504. doi:10.1093/neuonc/not242

79. Lane HA, Wood JM, Mcsheehy PM, et al. mTOR inhibitor RAD001 (everolimus) has antiangiogenic/vascular properties distinct from a VEGFR tyrosine kinase inhibitor. Clin Cancer Res. 2009;15(5):1612. doi:10.1158/1078-0432.CCR-08-2057

80. Karajannis MA, Legault G, Hagiwara M, et al. Phase II study of everolimus in children and adults with neurofibromatosis type 2 and progressive vestibular schwannomas. Neuro Oncol. 2014;16 (2):292-297. doi:10.1093/neuonc/not150

81. Goutagny S, Raymond E, Esposito-Farese M, et al. Phase II study of mTORC1 inhibition by everolimus in neurofibromatosis type 2 patients with growing vestibular schwannomas. J Neurooncol. 2015;122(2):313-320. doi:10.1007/s11060-014-1710-0

82. Pozzobon T, Goldoni G, Viola A, Molon B. CXCR4 signaling in health and disease. Immunol Lett. 2016;177:6-15. doi:10.1016/j. imlet.2016.06.006

83. Bar-Shavit R, Maoz M, Kancharla A, et al. G protein-coupled receptors in cancer. Int J Mol Sci. 2016;17(8):1320. doi:10.3390/ ijms 17081320

84. Breun M, Schwerdtfeger A, Martellotta DD, Kessler AF, Hagemann C. CXCR4: a new player in vestibular schwannoma pathogenesis. Oncotarget. 2018;9(11):9940-9950. doi:10.18632/ oncotarget.24119

85. Breun M, Monoranu CM, Kessler AF, et al. [68Ga]-pentixafor PET/ CT for CXCR4-mediated imaging of vestibular schwannomas. Front Oncol. 2019;9:503. doi:10.3389/fonc.2019.00503 
86. Dilwali S, Kao SY, Fujita T, Landegger LD, Stankovic KM. Nonsteroidal anti-inflammatory medications are cytostatic against human vestibular schwannomas. Transl Res. 2015;166(1):1-11. doi:10.1016/j.trsl.2014.12.007

87. Bujung H, Krusche CA, Schwabe K. Cyclooxygenase-2 supports tumor proliferation in vestibular schwannomas. Neurosurgery. 2011;68(4):1112-1117. doi:10.1227/NEU.0b013e318208f5c7

88. Nakanishi M, Rosenberg DW. Multifaceted roles of PGE2 in inflammation and cancer. Semin Immunopathol. 2013;35 (2):123-137. doi:10.1007/s00281-012-0342-8

89. Kandathil CK, Dilwali S, Wu CC, et al. Aspirin intake correlates with halted growth of sporadic vestibular schwannoma in vivo. Otol Neurotol. 2014;35(2):353-357. doi:10.1097/ mao.0000000000000189

90. Guerrant W, Kota S, Troutman S, et al. YAP mediates tumorigenesis in neurofibromatosis type 2 by promoting cell survival and proliferation through a COX-2-EGFR signaling axis. Cancer Res. 2016;76(12):3507-3519. doi:10.1158/0008-5472.can-15-1144

91. Wahle BM, Hawley ET, He Y, et al. Chemopreventative celecoxib fails to prevent schwannoma formation or sensorineural hearing loss in genetically engineered murine model of neurofibromatosis type 2. Oncotarget. 2018;9(1):718-725. doi:10.18632/ oncotarget.22002

92. MacKeith S, Wasson J, Baker C, et al. Aspirin does not prevent growth of vestibular schwannomas: a case-control study. Laryngoscope. 2018;128(9):2139-2144. doi:10.1002/lary.27114

93. Behling F, Ries V, Skardelly M, et al. COX2 expression is associated with proliferation and tumor extension in vestibular schwannoma but is not influenced by acetylsalicylic acid intake. Acta Neuropathol Commun. 2019;7(1):105. doi:10.1186/s40478019-0760-0

94. Hunter JB, O'Connell BP, Wanna GB, et al. Vestibular schwannoma growth with aspirin and other nonsteroidal anti-inflammatory drugs. Otol Neurotol. 2017;38(8):1158-1164. doi:10.1097/mao.0000000000001506

95. Muller DN, Heissmeyer V, Dechend R, et al. Aspirin inhibits NF-kappa B and protects from angiotensin II-induced organ damage. FASEB J. 2001;15(8):1822-1824. doi:10.1096/fj.000843fje

96. Gehlhausen JR, Hawley E, Wahle BM, et al. A proteasome-resistant fragment of NIK mediates oncogenic NF-kappa B signaling in schwannomas. Hum Mol Genet. 2019;28(4):572-583. doi:10.1093/hmg/ddy361

97. Van Gompel JJ, Agazzi S, Carlson ML, et al. Congress of neurological surgeons systematic review and evidence-based guidelines on emerging therapies for the treatment of patients with vestibular schwannomas. Neurosurgery. 2018;82(2):E52-E54. doi:10.1093/ neuros/nyx 516
98. Grunberg SM, Weiss MH, Russell CA, et al. Long-term administration of mifepristone (RU486): clinical tolerance during extended treatment of meningioma. Cancer Invest. 2006;24 (8):727-733. doi:10.1080/07357900601062339

99. Check JH, Wilson C, Cohen R, Sarumi M. Evidence that mifepristone, a progesterone receptor antagonist, can cross the blood brain barrier and provide palliative benefits for glioblastoma multiforme grade IV. Anticancer Res. 2014;34(5):2385-2388. doi:10.1038/nrc3733

100. Sonam D, Briët MC, Kao S-Y. Preclinical validation of anti-nuclear factor-kappa B therapy to inhibit human vestibular schwannoma growth. Mol Oncol. 2015;9(7):1359-1370. doi:10.1016/j.molonc.2015.03.009

101. Sagers JE, Brown AS, Vasilijic S, et al. Publisher correction: computational repositioning and preclinical validation of mifepristone for human vestibular schwannoma. Sci Rep. 2018;8 (1):17449. doi:10.1038/s41598-018-36016-9

102. Wang Y, Zhang Q, Wang B, Li P, Liu P. LiCl treatment induces programmed cell death of schwannoma cells through AKT- and mTOR-mediated necroptosis. Neurochem Res. 2017;42 (8):2363-2371. doi:10.1007/s11064-017-2256-2

103. Spear SA, Burns SS, Oblinger JL, et al. Natural compounds as potential treatments of NF2-deficient schwannoma and meningioma: cucurbitacin D and goyazensolide. Otol Neurotol. 2013;34(8):1519-1527. doi:10.1097/MAO.0b013e3182956169

104. Kim JY, Song JJ, Kwon BM, Lee JD. Tanshinone IIA exerts antitumor activity against vestibular schwannoma cells by inhibiting the expression of hypoxia-inducible factor-1 alpha. Mol Med Rep. 2015;12(3):4604-4609. doi:10.3892/mmr.2015.3932

105. Yang P, Sun D, Jiang F. Ailanthone promotes human vestibular schwannoma cell apoptosis and autophagy by downregulation of miR-21. Oncol Res. 2018;26(6):941-948. doi:10.3727/ $096504018 \times 15149775533331$

106. Ren Y, Sagers JE, Landegger LD, Bhatia SN, Stankovic KM. Tumor-penetrating delivery of siRNA against TNF $\alpha$ to human vestibular schwannomas. Sci Rep. 2017;7(1):12922. doi:10.1038/ s41598-017-13032-9

107. Ouerdani A, Goutagny S, Kalamarides M, Troconiz IF, Ribba B. Mechanism-based modeling of the clinical effects of bevacizumab and everolimus on vestibular schwannomas of patients with neurofibromatosis type 2. Cancer Chemother Pharmacol. 2016;77(6):1263-1273. doi:10.1007/s00280-016-3046-2

108. Pecina-Slaus N. Merlin, the NF2 gene product. Pathol Oncol Res. 2013;19(3):365-373. doi:10.1007/s12253-013-9644-y

\section{Publish your work in this journal}

Drug Design, Development and Therapy is an international, peerreviewed open-access journal that spans the spectrum of drug design and development through to clinical applications. Clinical outcomes, patient safety, and programs for the development and effective, safe, and sustained use of medicines are a feature of the journal, which has also been accepted for indexing on PubMed Central. The manuscript management system is completely online and includes a very quick and fair peer-review system, which is all easy to use. Visit http://www. dovepress.com/testimonials.php to read real quotes from published authors. 